\title{
The role of varicella zoster virus immediate-early proteins in latency and their potential use as components of vaccines
}

\author{
Sadzot-Delvaux C, Rentier B
}

Department of Microbiology, Fundamental Virology, Liege University, Sart Tilman-Liege, Belgium

Summary. Varicella zoster virus immediate-early (IE) proteins are intracellular regulators of viral gene expression. Some of them (IE62 and IE63) are found in large amounts in infected cells but are also components of the virion tegument. Several IE and early genes are transcribed during latency, while late genes are not. Recently, we demonstrated the presence of protein IE 63 in dorsal root ganglia of persistently infected rats as well as in normal human ganglia; other IE proteins have been found since in human ganglia. Cell-mediated immunity (CMI) to IE 62 has been evidenced. We found both humoral immunity and CMI to IE 63 in immune adults. In elderly zoster-free individuals, CMI to IE 63 remained high. The differences in the CMI to IE 63 among young adults, elderly people and immunocompromized patients have to be analyzed according to their status relative to zoster, to determine whether the decrease in CMI, particularly to IE proteins, could be responsible for viral reactivation and for the onset of shingles. Hopefully, the waning of the CMI to VZV IE 63 and perhaps to other IE proteins could become a predictive marker for herpes zoster and reimmunization, not only with the vaccine strain, but also with purified IE proteins could help prevent zoster at old age.

\section{Introduction}

Varicella zoster virus (VZV) has long been considered as a virus whose functioning could be deduced from that of herpes simplex virus (HSV), the prototype of Alphaherpesviruses, which is easy to produce in vitro and for which experimental models are available. Indeed VZV shares many morphological and biological properties with HSV and all other alphaherpesviruses. The most interesting characteristic certainly is the fact that, following primary infection, the virus can reach sensory ganglia and remain latent in the peripheral nervous system for many years before being reactivated and producing a rash, usually restricted to a single der-matoma.

However, it is now obvious that the mechanisms involved in VZV latency and reactivation are not identical to and perhaps not even similar to those described for HSV. HSV-1 remains latent in neurons only, and its latency is characterized by the accumulation of antisense latency-associated transcripts (LATs) in the nucleus of infected cells. Although these transcripts are thought to contain at least one open reading frame, no corresponding protein has been detected so far and it is still not clear whether the LATs play a role in the induction or in the maintenance of latency, while they could be involved in viral reactivation [44]. These characteristics are shared by the other alphaherpesviruses such as pseudorabies virus, equine herpesvirus-1 or bovine herpesvirus-1 but not by VZV, whose genome lacks any homolog of the HSV LAT-encoding sequence.

In situ hybridization and Northern blot analysis have provided evidence for a restricted transcription of the VZV genome during latency: both $\alpha$ (ORFs 4, 62 and 63) and putative $\beta$ genes (ORFs 29 and 21) are transcribed during latency while no $\gamma$ gene is $[9-11,31,43]$. The viral proteins corresponding to these transcripts have now been detected in rat [12] and in latently infected human ganglia [28, 30]. Three IE proteins (IE 4, 62 and 63) and two E proteins (ORF21p and ORF29p) accumulate in latently infected cells while no late protein seems to be expressed.

\section{Key roles of the immediate-early proteins in productive infection}

The VZV replication cycle can be subdivided into three phases: (1) virus adsorption and entry, (2) viral gene transcription and translation and (3) viral assembly and egress. Once the virus has penetrated the cell by fusion of its envelope with the plasma membrane, involving interactions between viral glycoproteins and cell receptors, the nucleocapsid reaches a nuclear pore through which the viral genome is released into the nucleoplasm. Viral genes are transcribed in the nucleus and transcripts are translated in the cytoplasm in three successive phases. A first wave leads to the very early expression 
of ORFs 4, 61, 62 and 63, in the absence of de novo protein synthesis. The proteins produced, called immediate-early proteins (IE), migrate back into the nucleus and induce the expression of a second class of proteins called early (E), mainly the enzymes involved in viral DNA replication. The third and last wave of protein expression occurs after DNA replication and results in the synthesis of late (L) proteins that will constitute the viral particle. The capsids are assembled in the nucleus, wrapped around the newly replicated DNA before acquiring an envelope and being released.

In this highly controlled process, the expression of the IE proteins is certainly the most critical step since these proteins play a key role in the regulation of expression of most other viral genes. Moreover, except for ORF6 lp, these proteins are found associated with purified virus particles [23, 24] and could constitute important targets for the immune system.

\section{IE 62}

ORF62p, a $175 \mathrm{kDa}$ protein encoded by ORF 62 and also by ORF 71, is present in large amounts in the viral tegument [24] and thus brought in by the incoming virus. It is expressed as a nuclear IE phosphoprotein, thus it is called IE 62 and it exerts an important regulatory function in VZV replication, as evidenced by transient expression experiments demonstrating that it is capable of transactivating genes of all classes and increasing viral DNA infectivity [21, 38, 41]. Moreover, IE 62 regulates its own promoter $[5,16]$. However, these regulatory properties appear to be dose-dependent because IE 62 can positively or negatively regulate the expression of other genes, depending on its concentration.

However, IE 62 does probably not act on its own, but in synergy with other IE proteins or even with cell proteins. A direct interaction with IE 4 specifically modifies the intracellular localization of the latter by transporting it to the nucleus [14]. Based on these data, it seems reasonable to propose that IE 62 , brought in at a low concentration by the incoming virus, initiates the IE phase by transacti-vating the expression of $\alpha$ genes. In a second step, IE 62 could participate in the activation of $\beta$ genes and later of 7 genes. Due to its autoactivating properties, its intracellular concentration increases progressively and its expression is thereby down-regulated.

\section{IE 4}

ORF4p, a $55 \mathrm{kDa}$ protein, is also present in large amounts in the viral tegument [23] and produced very early on in infected cells [13]. Its localization is mostly cytoplasmic but thanks to a direct interaction with IE 62, IE 4 can be transported to the nucleus [13]. IE 4 transactivates promoters of all three classes of genes, either on its own or in synergy with IE 62 [ 15], but it has no demonstrable transrepressing activity [37]. Its transactivating properties could require the presence of other functional cellular proteins.

\section{IE 63}

ORF63p is a $45 \mathrm{kDa}$ phosphoprotein encoded by genes 63 and 72. It is a component of the viral tegument, shown to be a true IE protein and it is strongly expressed during lytic infection in cell culture as well as in skin lesions $[12,23,34]$. Its localization is mostly nuclear, but it can also be detected in the cytoplasm of infected cells [12]. Even though IE 63 shows a slight repression of IE 4 transactivating properties on the IE 62 promoter [12], it lacks significant transactivating properties and its role at the very beginning of the replicative cycle has not yet been elucidated.

\section{ORF61p}

The phosphoprotein encoded by ORF 61 (ORF61p, 62-65 kDa) has been considered as an IE protein only on the basis on its homology with HSV-1 ICP-0, but an experimental demonstration of its IE nature has not yet been provided. Contrary to the three other IE proteins, ORF61p does not belong to the viral tegument [23]. It enhances infectivity of VZV and HSV-1 DNA as shown by transient expression experiments [32] and, depending on its cellular concentration and on host cell lines, it can either repress or transactivate the functions of IE 4 and IE 62 on other VZV gene promoters [8, 32, 33]. 


\section{Latency}

Besides their functional properties as regulatory proteins in productive infection, proteins IE 4, 62 and 63 appear to be of great interest because they are also expressed in large amounts during latency. An expression of viral proteins has never been described during alphaherpesvirus latency, but it has been demonstrated for IE 63, first in an animal model [12, 39] then in humans [30]. Later, other IE or E proteins have been detected in latently infected human cells [28]. Mostly intranuclear during productive infection according to their functions, these proteins are detected predominantly in the cytoplasm of latently infected cells but they become detectable in nuclei when the virus reactivates. The reasons for this modified distribution during latency are still not understood. It is also not clear whether cytoplasmic sequestration is the result of a failed process that normally carries them to the nucleus where they perform their regulatory tasks or whether their accumulation by itself inhibits replication. Cytoplasmic overloading of these proteins during latency suggests new hypotheses for the establishment and maintenance of VZV latency [27]: the virus enters the cell as in productive infection and the cycle initiates by the expression of some of the regulatory IE proteins (IE 4, 62 and 63) which probably migrate to the nucleus to exert their regulatory functions, but they are in such low quantities that they remain undetectable.

Even a low amount of IE proteins migrating to the nucleus allows the expression of E proteins encoded by ORFs 21 and 29 [28], which also accumulate in large amounts in the cytoplasm. It is not known whether other E proteins are expressed and whether viral DNA replication occurs at all, but so far, no L protein has been detected during latency.

The mechanisms involved in this process have yet to be identified, but it is tempting to conclude that cells in which the virus becomes latent lack the necessary elements to process IE proteins and to give them the conformation by which they become functional. Phosphorylation or other post-translational modifications are candidate impaired process mechanisms. It is also possible that some cellular components interact with viral proteins or with viral promoters that can interfere with the replication cycle and lead to replicative arrest. For instance, Patel and collaborators have demonstrated that the isoforms of the cellular transcription factor Oct-2 expressed specifically in neuronal cells can inhibit basal activity of the VZV IE 62 promoter in neuronal cells but not in other cell types, suggesting a cell type-specificity [35]. This mechanism could be of particular importance for the onset of VZV latency in sensory ganglia.

However, such explanations still need experimental confirmation and must take into account the observation that inhibition is reversible in yet undetermined conditions when reactivation occurs. Another important difference between VZV and HSV latency is the nature of the cells in which the virus remains latent. HSV clearly resides in neurons only whereas the precise localization of persistent VZV is still debated: using in situ hybridization or in situ PCR, evidence of latency in neuronal cells $[17,20]$, in non neuronal cells $[11,31]$ or in both cell types $[26,29]$ has been shown. Animal models did not allow elucidation of this issue because in mice and rats the viral genome was detected in both cell types $[39,45]$.

\section{Immunogenicity of the IE proteins}

One of the parameters of obvious importance for the control of virus infection is host immunity. Clinical observations have shown that the frequency and severity of viral reactivations increase in patients whose cell-mediated immunity (CMI) is impaired because of age, pathological disorders or immunosuppressive treatments prior to transplantation $[3,6,18]$.

Previous studies have shown that viral tegument proteins, including IE 62 and 63, and the major glycoproteins, are important targets for CMI to VZV. They elicit a long term humoral and cellular immune response after natural VZV infection $[1,4,40]$. T lymphocytes from most VZV naturally immune donors proliferate in vitro after stimulation with these proteins and they can lyse autologous target cells that express IE 62, 63, gC, gE, gG or gl.

The critical role of immune control has been suggested by Hope-Simpson as early as 1965 [19]: VZV primary infection appears to be limited by host "resistance" (immune response) that remains high for many years, with a slow decrease over time. This decrease could, however, be partly counterbalanced by frequent viral reactivations or contact with infected individuals, which would contribute to maintaining an efficient immunity until reaching a critical level under which the host resistance would be too low to control viral reactivation. This hypothesis, based only on clinical observations is still valid today even if it appears now that it is mostly the CMI that limits viral reactivation. Indeed, virus 
reactivates in spite of high anti-VZV antibody titers and the zoster episode is not correlated with hypogammaglobulinsemia.

It is tempting to think that the expression of viral proteins in latently infected cells constitutes another way to trigger the immune response and could thus contribute to maintain it at a protective level. In this context, it will be of interest to characterize the immune response to viral proteins expressed during latency, in the elderly and in immunocompromised patients who have a high incidence of herpes zoster. It is well known that the CMI is often impaired with age, as documented using in vitro PBMC stimulation by whole VZV antigens [18]. Such a study has not been performed with purified VZV proteins and in particular with proteins expressed in latently infected cells.

However, many questions are raised by this hypothesis of a role for the viral 'latency proteins' in maintaining a specific immune response. The nervous system is indeed protected from immune recognition by anatomical barriers and neurons lack classical MHC molecules at their surfaces . On the contrary, satellite cells surrounding neurons express MHC and they could play an important role in antigen presentation. It is thus critical to define clearly in which cells the virus remains quiescent. So far, during latency, IE 63 has been observed only in neuron cytoplasms. If neurons are the only cells expressing viral antigens, the mechanisms leading to the recognition of viral peptides must be clarified. It is possible that non-classical MHC proteins are being expressed at the cell surface in response to viral infection, as it has been suggested for HSV [36]. However, in HSV-infected cells, peptide presentation by MHC molecules appears to be impaired because of a viral protein that inhibits peptide processing $[22,42]$. VZV has been shown to selectively downregulate cell-surface MHC class I expression on human fibroblast cells and to inhibit IFN-7 induction of MHC class II cell surface expression [2].

Enhancing the immune response to IE 63 may become an important strategy for preventing VZV reactivation from latency. If so, IE 63 could be a suitable candidate as an additive for a VZV vaccine to be given to ageing adults in order to boost their immunity and to prevent herpes zoster [7, 25].

Because recognition by the immune system of proteins expressed during latency, proteins such as IE 62 and 63 , could play a role in the control of latency, it must be documented using animal models or by studies involving a larger number of donors, particularly donors with a high probability of reactivation of the virus.

\section{Acknowledgements}

We wish to thank Drs. M. Takahashi and K. Yamanishi, the VZV Research Foundation and the "Fonds de la Recherche Scientifique Medicale" of Belgium for their support.

\section{References}

[1]. Ahn K, Meyer TH, Uebel S, Sempe S, Djaballah H, Yang Y, Peterson PA, Fruh K, Tampe R (1996) Molecular mechanism and species specificity of TAP inhibition by herpes simplex virus ICP47. EMBO J 15: $3247-3255$

[2]. Arvin AM, Kinney-Thomas E, Shriver K, Grose C, Koropchak CM, Scranton E, Wittek AE, Diaz PS (1986) Immunity to varicella-zoster viral glycoproteins, gp I (gp 90/58) and gp III (gp 118), and to a nonglycosylated protein, p 170. J Immunol 137: 1346-1351

[3]. Arvin AM, Pollard RB, Ramussen LE, Merigan TC (1980) Cellular and humoral immunity in lymphoma patients. J Clin Invest 65: 869

[4]. Arvin AM, Sharp M, Smith S, Koropchak CM, Diaz PS, Kinchongton P, Ruyechan W (1991) Equivalent recognition of a varicella-zoster virus immediate early protein (IE62) and glycoprotein I by cytotoxic T lymphocytes of either CD4+ or CD8+ phenotype. J Immunol 146: 257-264

[5]. Baudoux L, Defechereux P, Schoonbroodt S, Merville MP, Rentier B, Piette J (1995) Mutational analysis of varicella-zoster virus major immediate-early protein IE62. Nucleic Acids Res 23: 13411349

[6]. Berger R, Florent G, lust M (1980) Decrease of the lymphoproliferative response to varicellazoster vims antigen in the aged. Infect Immun 32: 24-27

[7]. Berger R, Trannoy E, Hollander G, Bailleux F, Rudin C, Creusvaux H (1998) A dose-response study of a live attenuated varicella-zoster virus (Oka strain) vaccine administered to adults 55 years of age and older. J Infect Dis 178 [Suppl] 1: S99-103

[8]. Cabirac GF, Mahalingam R, Wellish M, Gilden DH (1990) Trans-activation of viral tk promoters by proteins encoded by varicella zoster virus open reading frames 61 and 62. Virus Res 15: 57-68 
[9]. Cohrs RJ, Barbour M, Gilden DH (1996) Varicella-zoster virus (VZV) transcription during latency in human ganglia: detection of transcripts mapping to genes 21, 29, 62, and 63 in a cDNA library enriched for VZV RNA. J Virol 70: 2789-2796

[10]. Cohrs RJ, Srock K, Barbour MB, Owens G, Mahalingam R, Devlin ME, Wellish M, Gilden DH (1994) Varicella-zoster virus (VZV) transcription during latency in human ganglia: construction of a cDNA library from latently infected human trigeminal ganglia and detection of a VZV transcript. J Virol 68: 7900-7908

[11]. Croen KD, Ostrove JM, Dragovic LJ, Straus SE (1988) Patterns of gene expression and sites of latency in human nerve ganglia are different for varicella-zoster and herpes simplex viruses. Proc Natl Acad Sci USA 85: 9773-9777

[12]. Debrus S, Sadzot-Delvaux C, Nikkels AF, Piette J, Rentier B (1995) Varicella-zoster virus gene 63 encodes an immediate-early protein that is abundantly expressed during [13]. Defechereux $\mathrm{P}$, Debrus S, Baudoux L, Rentier B, Piette J (1997) Varicella-zoster virus open reading frame 4 encodes an immediate-early protein with posttranscriptional regulatory properties. J Virol 71: 7073-7079 [14]. Defechereux P, Debrus S, Baudoux L, Schoonbroodt S, Merville MP, Rentier B, Piette J (1996) Intracellular distribution of the ORF4 gene product of varicella-zoster virus is influenced by the IE62 protein. J Gen Virol 77: 1505-1513

[15]. Defechereux P, Melen L, Baudoux L, Merville-Louis MP, Rentier B, Piette J (1993)

Characterization of the regulatory functions of varicella-zoster virus open reading frame 4 gene product. J Virol 67: 4379-4385

[16]. Disney GH, McKee TA, Preston CM, Everett RD (1990) The product of varicella-zoster virus gene 62 autoregulates its own promoter. J Gen Virol 71: 2999-3003

[17]. Gilden DH, Rozenman Y, Murray R, Devlin M, Vafai A (1987) Detection of varicella-zoster virus nucleic acid in neurons of normal human thoracic ganglia. Ann Neurol 22: 377-380

[18]. Hayward AR, Herberger M (1987) Lymphocyte responses to varicella zoster virus in the elderly. J Clin Immunol 7: 174-178

[19]. Hope-Simpson RE (1965) The nature of herpes zoster: a long-term study and a new hypothesis. Proc R Soc Med 58: 9-20

[20]. Hyman RW, Ecker JR, Tenser RB (1983) Varicella-zoster virus RNA in human trigeminal ganglia. Lancet 2: 814-816

[21]. Inchauspe G, Nagpal S, Ostrove JM (1989) Mapping of two varicella-zoster virus-encoded genes that activate the expression of viral early and late genes. Virology 173: 700-709

[22]. Jugovic P, Hill AM, Tomazin R, Ploegh H, Johnson DC (1998) Inhibition of major

histocompatibility complex class I antigen presentation in pig and primate cells by herpes simplex virus type 1 and 2 ICP47. J Virol 72: 5076-5084

[23]. Kinchington PR, Bookey D, Turse SE (1995) The transcriptional regulatory proteins encoded by varicella-zoster virus open reading frames (ORFs) 4 and 63, but not ORF 61, are associated with purified virus particles. J Virol 69: 4274-4282

[24]. Kinchington PR, Hougland JK, Arvin AM, Ruyechan WT, Hay J (1992) The varicella-zoster virus immediate-early protein IE62 is a major component of virus particles. J Virol 66:359-366 [25]. Levin MJ, Barber D, Goldblatt E, Jones M, LaFleur B, Chan C, Stinson D, Zerbe GO, Hayward AR (1998) Use of a live attenuated varicella vaccine to boost varicella-specific immune responses in seropositive people 55 years of age and older: duration of booster effect. J Infect Dis 178 [Suppl 1]: S109-S112

[26]. Lungu O, Annunziato PW, Gershon A, Staugaitis SM, Josefson d, Larussa P, Silverstein SJ (1995) Reactivated and latent varicella-zoster virus in human dorsal root ganglia. Proc Natl Acad Sci USA 92: 10980-10984

[27]. Lungu O, Annunziato PW (1999) Varicella-zoster virus: latency and reactivation. In: Wolff MH, Schiinemann S, Schmidt A (eds) Varicella-zoster virus. Molecular biology, pathogenesis and clinical aspects. Karger, Basel, pp 61-75

[28]. Lungu O, Panagiotidis CA, Annunziato PW, Gershon A A, Silverstein SJ (1998) Aberrant intracellular localization of varicella-zoster virus regulatory proteins during latency. Proc Natl Acad Sci USA 95: 7080-7085

[29]. Mahalingam R, Kennedy PGE, Gilden DH (1999) The problems of latent varicella eoster virus in human ganglia:precise cell location and viral content. J Neurovirol 5: 445-446

[30]. Mahalingam R, Wellish M, Cohrs R, Debrus S, Piette J, Rentier B, Gilden DH (1996) Expression of protein encoded by varicella-zoster virus open reading frame 63 in latently infected human ganglionic neurons. Proc Natl Acad Sci USA 93: 2122-2124

[31]. Meier JL, Holman RP, Croen KD, Smialek JE, Straus SE (1993) Varicella-zoster virus transcription in human trigeminal ganglia. Virology 193: 193-200 
[32]. Moriuchi H, Moriuchi M, Straus SE, Cohen JI (1993) Varicella-zoster virus (VZV) open reading frame 61 protein transactivates VZV gene promoters and enhances the infectivity of VZV DNA. J Virol 67: 4290-4295

[33]. Nagpal S, Ostrove JM (1991) Characterization of a potent varicella-zoster virus-encoded transrepressor. J Virol 65: 5289-5296

[34]. Nikkels AF, Debrus S, Sadzot-Delvaux C, Piette J, Rentier B, Pierard GE (1995) Immunohistochemical identification of varicella-zoster virus gene 63-encoded protein (IE63) and late (gE) protein on smears and cutaneous biopsies: implications for diagnostic use. J Med Virol 47: 342-347 [35]. Patel Y, Gough G, Coffin RS, Thomas S, Cohen JI, Latchman DS (1998) Cell type specific repression of the varicella zoster virus immediate early gene 62 promoter by the cellular Oct-2 transcription factor. Biochim Biophys Acta 1397: 268-274

[36]. Pereira RA, Tscharke DC, Simmons A (1994) Upregulation of class I major histocompatibility complex gene expression in primary sensory neurons, satellite cells, and Schwann cells of mice in response to acute but not latent herpes simplex virus infection in vivo. J Exp Med 180: 841-850 [37]. Perera LP, Kaushal S, Kinchington PR, Mosca JD, Hayward GS, Straus SE (1994) Varicellazoster virus open reading frame 4 encodes a transcriptional activator that is functionally distinct from that of herpes simplex virus homology ICP27. J Virol 68: 2468-2477

[38]. Perera LP, Mosca JD, Sadeghi-Zadeh M, Ruyechan WT, Hay J (1992) The varicella-zoster virus immediate early protein, IE62, can positively regulate its cognate promoter. Virology 191:346-354

[39]. Sadzot-Delvaux C, Debrus S, Nikkels A, Piette J, Rentier B (1995) Varicella-zoster virus latency in the adult rat is a useful model for human latent infection. Neurology 45: S18-S20

[40]. Sadzot-Delvaux C, KinchingtonPR, Debrus S, RentierB, Arvin AM (1997) Recognition of the latency-associated immediate early protein IE63 of varicella-zoster virus by humanmemory $\mathrm{T}$ lymphocytes. J Immunol 159: 2802-2806

[41]. Shiraki K, Hyman RW (1987) The immediate early proteins of varicella-zoster virus. Virology 156: $423-426$

[42]. Tomazin R, Hill AB, Jugovic P, York I, van Endert P, Ploegh HL, Andrews DW, Johnson DC (1996) Stable binding of the herpes simplex virus ICP47 protein to the peptide binding site of TAP. EMBO J 15: 3256-3266

[43]. Vafai A, Murray RS, Wellish M, Devlin M, Gilden DH (1988) Expression of varicella-zoster virus and herpes simplex virus in normal human trigeminal ganglia. Proc Natl Acad Sci USA 85: 23622366

[44]. Whitley RJ (1996) Herpes simplex virus. In: Fields BN, Knipe DM, Howley PM (eds) Virology. Lippincott-Raven, New York, pp 2297-2342

[45]. Wroblewska Z, Valyi-Nagy T, Otte J, Dillner A, Jackson A, Sole DP, Fraser NW (1993) A mouse model for varicella-zoster virus latency. Microb Pathog 15: 141-151 